\title{
Proceeding
}

Supplementary Issue: Spring Conferences of Sports Science. 15th Convention and Workshop of the International Network of Sport and Health Science, 5-8 June 2019. University of Las Palmas de Gran Canaria, Las Palmas de Gran Canaria, Spain.

\section{Physical education status in European school's curriculum, extension of educational offer and planning}

\author{
CRISTIANA D'ANNA , PASQUALINA FORTE, FILIPPO GOMEZ PALOMA \\ Department of Human, Philosophical and Education Science, University of Salerno, Italy
}

\begin{abstract}
The new Global Action Plan on Physical Activity 2018-2030 of the WHO promotes sporting and physical activity as a leading factor for mental health, quality of life and wellness. The document highlights the beneficial effects of regular physical activity and the need to achieve a paradigm shift in supporting and evaluating people regularly, according to the ability and across the life course. A recent systematic review confirms that school health programs promoting active lifestyles among children and adolescents may contribute to the improvement of health-related quality of life. The educational environment plays a key role: physical education is part of all central curriculum frameworks in the EU, and is compulsory in primary and secondary education. The time allocated to physical education in some member states of the EU is insufficient to cover the recommendations of the WHO, so as to assume a marginal role in School Curriculum. This study aims to outline the current state of physical education in European school systems by drawing a comparative framework on topics related to the issue: national and European strategies, large-scale projects, teacher education, status of physical education in national curricula and in extracurricular activity, pupils evaluation and ongoing reform projects. We performed a meta-analysis study analysing national documents of the various member states, international reports of European organization and some international reviews. The results of the study underline strengths and weaknesses of the various national situations to identify the main critical problems and to highlight the potential of sustainable initiatives already validated. Keywords: Physical education; Sport activity; European education system; Curriculum; Teacher education.
\end{abstract}

Cite this article as:

D'Anna, C., Forte, P., \& Gomez, F. (2019). Physical education status in European school's curriculum, extension of educational offer and planning. Journal of Human Sport and Exercise, 14(4proc), S805S817. doi:https://doi.org/10.14198/jhse.2019.14.Proc4.43

Corresponding author. Department of Human, Philosophical and Education Science, University of Salerno, Italy.

E-mail: cdanna@unisa.it

Supplementary Issue: Spring Conferences of Sports Science. 15th Convention and Workshop of the International Network of Sport and Health Science, 5-8 June 2019. University of Las Palmas de Gran Canaria, Las Palmas de Gran Canaria, Spain. JOURNAL OF HUMAN SPORT \& EXERCISE ISSN 1988-5202

(c) Faculty of Education. University of Alicante

doi:10.14198/jhse.2019.14.Proc4.43 


\section{INTRODUCTION}

Regular physical activity plays a key role in personality development, promoting psycho-physical well-being. The World Health Organization, in the document "Physical activity strategy for the WHO European Region 2016-2025" (WHO, 2015), underlines the importance of physical activity as a driving factor for the health and well-being of the European region, with particular attention to the incidence of non-communicable diseases, associated with insufficient levels of physical activity and sedentary behaviours. The document in the light of the guidelines for physical activity, recommends 150 minutes per week of aerobic activity for adults and at least 60 minutes per day of moderate to intense physical activity for young people and children. With the new Global Action Plan to promote physical activity - More active people for a healthier world - the WHO responds to the request of governments to have updated guidelines on effective policies to increase physical activity in the entire population. The global action model developed for the promotion of physical activity is composed of 4 strategic objectives: building active societies (social norms and behaviour); build active living environments (spaces and places); promote active lifestyles (programs and opportunities) and orient government systems towards the promotion of physical activity and health (political and government levers) (WHO, 2018).

This is because, in recent decades, data on physical inactivity and increased levels of physical inactivity, among individuals of developmental age, have increased considerably. Different international studies show that physical inactivity, a sedentary lifestyle and the possible and correlated obesity between children and adolescents are a widespread phenomenon worldwide. The incidence of juvenile overweight is stabilizing in several countries, with about $10 \%$ of overweight children and adolescents and $2-3 \%$ in conditions of obesity. Several regions and countries have particularly high rates of paediatric obesity: more than $30 \%$ of children and adolescents in the Americas, while about 20\% in Europe are overweight or obese. More than $30 \%$ of Italian children are overweight or obese (Gallotta et al., 2016). Similar results are reported in the OKkio alla Salute 2012 research data which shows that in Italy, the levels of physical inactivity and sedentary behaviour in Italian children are high, in fact only one child out of ten, of school age, practices adequate physical activity and only $18 \%$ of children carry out structured physical activity for more than 1 hour a week, while about $35 \%$ of children spend their time in sedentary activities (television viewing and video games) for more than 2 hours a day (High School Healthcare, 2012).

The educational environment plays a fundamental role, and that is why, physical education in the curriculum of primary and secondary school is an inescapable component of the educational process of the child and young person. The contribution of physical education and motor activities for the prevention of sedentary habits and the development of learning processes is widely highlighted in the literature (Colella, 2018). The contribution of physical education is essential for the global formation of the child's and young person's personality; the effects of teaching in primary and secondary schools are decisive both on the educational level and for the promotion of health and the implementation of preventive measures, above all following the studies that report a reduction in the levels of physical activity and an increase in overweight and obesity in developmental age (Di Maglie, 2017). Students in the classroom and study time are sedentary for about 7-8 hours a day and the school environment should provide an opportunity to ensure physical activity for a large number of children for long periods of time (Mantjes et al., 2012). Physical education and sport contribute to the integral growth of the person, direct towards a healthy lifestyle and generate physical and mental benefits. It is essential, therefore, to create the conditions to increase not only the time dedicated to the physical activities of pupils and students in schools but also to provide professionals with appropriate skills. Physical education is not limited to exercising physical skills nor is it merely a recreational function; the objectives that go beyond the field of physical education and sport, such as good health, healthy development of the person 
and social inclusion, make it all the more important to include the subject in the school curricula and give it more hours. (D'Anna, 2018).

Not surprisingly, the social value of physical education and sport has also been reaffirmed in various documents of the European Commission. (European Commission/EACEA/Eurydice, 2013). At European level, physical education is "compulsory in all national curricula, both primary and lower secondary. For almost all countries, the main objective of physical education is to foster the physical, personal and social development of children. It is often emphasized also the promotion of a healthy lifestyle In Ireland, Cyprus and Finland health education has become a compulsory subject, although the learning outcomes of physical education are closely linked to the main objectives, in some countries such as Germany, the Portugal, the United Kingdom and the Nordic countries are taught with an interdisciplinary approach, the central authorities of many countries have foreseen, in the curricula for the first years of primary education, basic motor activities such as walking, running, jumping and throwing. further develop these basic skills and expand them by involving more complex sports"(European Commission/EACEA/Eurydice, 2013).

\begin{abstract}
Aim
The present study aims to outline the current state of the art of physical education in European school systems by drawing a comparative framework on some topics closely related to the issue: national and European strategies, large-scale projects, teacher education, status of physical education in national curricula and in extracurricular activity, pupil assessment and ongoing reform projects.
\end{abstract}

\title{
MATERIALS AND METHODS
}

We performed a meta-analysis study and comparing national documents of the various member states, international reports of European organization and some international reviews.

The first phase of the study was devoted to the selection of scientific literature. The search was possible through various search engines; in particular, databases such as ScienceDirect, Google Scholar and ResearchGate have been used, as well as through the websites of the various EU member states and related education ministries.

The selected European documents and articles range from 2008 to 2018. Detailed national data were found in country information sheets published in 2018 by the WHO Regional Office for Europe and by the European Commission, compared with the results of the EUPEA Seminar 2018, and where possible, verified by the website of the Ministry of Education.

\section{RESULTS}

The results of the study highlight the strengths and weaknesses of the various national situations to identify the main critical problem and highlights the potential of sustainable initiatives already validated. Table $n .1$ presents a good overview of curriculum hours in the European Union; table n. 2 includes successful national approaches with the aim of increasing not only the number of pupils who are physically active but also raising awareness of the benefits of physical activity. 
Table 1. Weekly hours dedicated to teaching physical education (P.E) and physical activity (P.A.) in European school curricula

\begin{tabular}{|c|c|c|}
\hline COUNTRY & PRIMARY SCHOOL & SECONDARY SCHOOL \\
\hline Austria & $\begin{array}{l}\text { Grades 1-2: 2-3 } \\
\text { Grades 3-4: } 2\end{array}$ & $\begin{array}{l}\text { Grades 5-6: 3-4 } \\
\text { Grades 7-8: 3 } \\
\text { Grades 9-12: 2-3 }\end{array}$ \\
\hline \multicolumn{3}{|l|}{ Belgium: } \\
\hline -French community & 2 & $2-3$ \\
\hline $\begin{array}{l}\text {-Flemish community } \\
\text {-German-speaking }\end{array}$ & 2 & 2 \\
\hline community & 2 & 2 \\
\hline Bulgaria & 3 & 3 \\
\hline Croatia & & In schools with a 4-year programme: 2 \\
\hline Groatia & Grades 4-8: 2 & In schools with a 3-year programme: 1 \\
\hline Cyprus & $\begin{array}{l}\text { Grades A, B, C, D ( } 6-10 \text { years): } 1.5 \\
\text { Grades E and St (11-12 years): } 1\end{array}$ & $\begin{array}{l}\text { Gymnasium ( } 13-15 \text { years) } 2-2.5 \\
\text { Lyceum ( } 16-18 \text { years) } 1-1.5\end{array}$ \\
\hline Czechia & 2 & 2 \\
\hline Denmark & $\begin{array}{l}\text { Grades 1-3: } 60 \mathrm{~h} / \text { year } \\
\text { Grades 4-6: } 90 \mathrm{~h} / \text { year } \\
\text { Grades 7-9: } 60 \mathrm{~h} / \text { year }\end{array}$ & \\
\hline Estonia & $\begin{array}{l}\text { Two or three } 45-\mathrm{min} \text { lessons per } \\
\text { week }\end{array}$ & $\begin{array}{l}\text { During the } 3 \text { years of secondary school, students should have } 35 \text { courses } \\
\text { of } 45 \text { min of P.E. }\end{array}$ \\
\hline Finland & $\begin{array}{l}\text { Two or three } 45-\text { min lessons per } \\
\text { week }\end{array}$ & $\begin{array}{l}\text { Two mandatory courses of about } 38 \text { hours each of P.E. and three national } \\
\text { volunteer courses }\end{array}$ \\
\hline France & 3 & $2-3$ \\
\hline Germany & 3 & 3 \\
\hline Greece & 3 & 2 \\
\hline Hungary & 5 & 5 \\
\hline Ireland & 1 & 2 \\
\hline Italy & 1 & 2 \\
\hline Latvia & 2 & 3 \\
\hline Lithuania & $2-3$ & $2-3$ \\
\hline Luxembourg & $\begin{array}{l}\text { First year: } 0 \\
\text { Next } 4 \text { years: } 2 \\
\text { Last } 2 \text { years: } 2\end{array}$ & $\begin{array}{l}\text { First year: } 3 \\
\text { Next } 5 \text { years: } 2 \\
\text { Last } 2 \text { or } 3 \text { years: } 2\end{array}$ \\
\hline Malta & 2 & 2 \\
\hline Netherlands & 2 & 2.5 \\
\hline Poland & $\begin{array}{l}\text { Grades 1-3: } 3 \\
\text { Grades 4-8: } 4\end{array}$ & 3 \\
\hline Portugal & 3 & 2.25 \\
\hline Romania & 3 & 3 \\
\hline Slovakia & 3 & 3 \\
\hline Slovenia & $2-3$ & $1-3$ \\
\hline Spain & 2 & 2 \\
\hline Sweden & $\begin{array}{l}\text { School years 1-3:1.5 } \\
\text { School years 4-9: } 2\end{array}$ & $1-1.5$ \\
\hline United Kingdom & 2 & 2 \\
\hline
\end{tabular}


Table 2. School and extracurricular proposals implemented by EU member states for the promotion and implementation of sports practice and physical activity (P.A.)

\begin{tabular}{lll}
\hline Country & School strategies & Extracurricular strategies
\end{tabular}

\begin{tabular}{ll}
\hline & "Fit Sports Network Austria" \\
Austria & $\begin{array}{l}\text { The objective is to strengthen the promotion of P.A. for health } \\
\text { within sports facilities and integrate a daily P.A. activity lesson } \\
\text { into school programs, guided by local sports clubs and } \\
\text { qualified coaches. }\end{array}$ \\
Belgium & $\begin{array}{l}\text { Sport Flanders leads a project in which schools can request } \\
\text { financial support to open their sports infrastructure after school } \\
\text { hours, on weekends and during holidays. }\end{array}$
\end{tabular}

$\begin{array}{ll} & \text { Polygon for P.A. of schoolchildren } \\ \text { Croatia } & \text { It is a set of mobile equipment composed of } 25 \text { elements that } \\ \text { are easy to assemble and disassemble, to support teachers in } \\ \text { the providing P.E. and to meet the needs of students. } \\ \text { "All different - all equal" is a program led by the Ministry of } \\ \text { Cyprus } & \begin{array}{l}\text { Education and Culture in collaboration with the Cyprus } \\ \text { Football Association. A component are school tournaments to } \\ \text { increase opportunities for P.A. }\end{array}\end{array}$

$\begin{array}{ll} & \text { Tell me your story } \\ \text { Czech } & \begin{array}{l}\text { A campaign for schools and sports clubs aimed at rom children } \\ \text { and children at risk of social exclusion. Sports tournaments } \\ \text { Republic } \\ \text { and competitions of various disciplines have been organized, } \\ \text { of which ping pong, athletics and ball games have been the } \\ \text { most popular. }\end{array}\end{array}$

\section{5 minutes of daily P.A. in schools}

Denmark

In addition to P.E. classes, they are required 45 minutes of daily P.A. (about 150 hours / year) in primary and secondary public high schools to improve students' learning, health and well-being.

$\begin{array}{cl} & \text { Schools in motion } \\ \text { Estonia } & \begin{array}{l}\text { A multicomponent proposal for P.A. in schools, providing } \\ \text { active lessons, active transport, physical education lessons, } \\ \text { involving all school staff, students and parents in these active } \\ \text { solutions. }\end{array} \\ \text { Finland } & \text { "On the move" is a government action program launched in } \\ & \begin{array}{l}2010 \text { to establish a culture of P.A. in Finnish schools. Active } \\ \text { breaks and before and after school activities are key elements. }\end{array} \\ & \begin{array}{l}\text { Intervention centred on adolescents' P.A. and sedentary } \\ \text { behaviour (ICAPS) it is based on a socio-ecological approach } \\ \text { and involves different sectors and types of action, such as } \\ \text { Fotivation towards P.A., encourage social assistance to } \\ \text { promote P.A., motivating young people to increase their level } \\ \text { of practice providing the environmental conditions for } \\ \text { promoting P.A. inside and outside the school, in their free time } \\ \text { and in everyday life. }\end{array}\end{array}$

Germany
Sport after school pass (Sport na school pass) offers after-school sports at affordable prices for all secondary school students, with the aim of increasing their participation in sport, especially for those who are inactive.

The goal of the national health promotion program, "Healthy Living" is to create conditions in all counties that allow all citizens to reach the recommended levels of P.A. For children, activities are regularly organized in the parks during their free time.

Run for my health (2018) a great running event for secondary school students organized by the Ministry of Education and Culture, with the aim of motivating schoolchildren to increase their P.A outside school hours.

Ride2sCool is a registered association whose main purpose is to guarantee, maintain and further develop bicycle accessibility for students in the largest cities in the Czech Republic. The program aims to increase the active trip to school by children between 6 and age 14 and involves university students who act as guides and tutors during the trip to school.

The Danish Sports Policy (2016) guarantees all groups in society the opportunity to participate in sports or P.A.. The policy states that special efforts must be made to involve children, adolescents and adults who are not already involved in organized sports as well as in disabled or vulnerable groups that may have difficulty participating in the traditional settings of sports associations.

\section{Redesigning physical education}

Redesign physical education to include the promotion of P.A. throughout life, habits and the motivation to be active. The goal is to increase the health culture of all pupils on P.A.

The "National Plan for sport, health and well-being" (National Sports Santé Bien-Etre) led by the Ministry of Health and the Ministry of Sports, it is the key national policy to promote P.A.

National recommendations for P.A. and the promotion of P.A. were designed in the context of the national action plan "in the form", the national initiative to promote healthy diets and P.A.. 


Swimming school program is a program for $8-9$ year-olds as
a pilot project launched in Athens in 2015 and was later
extended throughout Greece, at the national level in 2018. The
program is part of each school's P.E. course.
Adeece
Adaptation of the Hungarian national student fitness test
(NETFIT®) to children with special educational needs it is
a physical fitness test supported by online software. Test data
are used to monitor individual and group changes in the state
of physical fitness of students with special educational needs.
Junior cycle well-being program
Theland
in three years of learning opportunities to improve the physical,
mental, emotional and social. The program includes P.E., civic
education, and social policy and health. The program is
mandatory for all post-primary schools in Ireland.
Classroom sports the project goal is to promote P.E. and P.A.
in primary schools, with the involvement of students, teachers,
school administrators and families.

\begin{tabular}{|c|c|}
\hline Latvia & $\begin{array}{l}\text { Everyone exercises a project with the aim to strengthen the } \\
\text { role of sport in society, to inspire children to engage in regular } \\
\text { P.A. and monitor the effects of exercise on their health. In } \\
\text { addition to two mandatory P.E. classes per week, three } \\
\text { optional lessons are scheduled per week, thus providing daily } \\
\text { P.A.. }\end{array}$ \\
\hline Lithuania & $\begin{array}{l}\text { "Spring of activeness" The goal of the project is to encourage } \\
\text { young adolescents to have physically active lifestyles by } \\
\text { offering experiential learning opportunities in informal P.A. } \\
\text { based on best practices of other countries. }\end{array}$ \\
\hline
\end{tabular}
Luxembourg Active schools it is a project to increase P.A. in elementary
and primary schools in Luxembourg.

Malta "Schools OnTheMove" is a multifaceted and dynamic program to promote and support participation in sport and P.A.. The program includes sessions of P.A., mainly on Saturday mornings, which are open to children aged $\leq 16$ years.

\section{"Sports for All"}

The goal of the program is to offer opportunities for the entire population to be physically active. Includes proposals for people with disabilities, preschool children, adolescents and adults and the elderly in mental health facilities.

In 2015, the Secretary of State for Sport has launched an infrastructure development program called the National Recreational Sports Park Health Program Several sports parks have been built according to predefined criteria.

National Sports Policy 2018-2027 Its three top-level objectives are: greater participation, more excellence and better capacity. An area of particular attention will be to increase the levels of participation in sport and P.A. of the entire population and to restrict existing gradients in gender, age, socio-economic status, disability and ethnicity.

There are no projects organized by the Ministry but by the various federations that operate at national level for the promotion and dissemination of sports.

Since 2017, the Center for Disease Prevention and Control has conducted interventions to promote P.A. with different objectives: strengthening the muscles involved in posture, teaching correct breathing techniques to children aged 7 and 8 and educating the elderly ( $\geq 54$ years) ) in P.A.

Lithuania has prepared a national strategy for sports development for the period 2011-2020, which promotes sport for all and is based on four themes: greater awareness of the benefits of P.A.; development of sports skills; development of sports infrastructure; and accessibility of sports infrastructure.

The "Sports Night" (Nut du Sport) is a national event launched in 2009. The municipalities are encouraged to offer all people the opportunity to engage in P.A., welcoming and festive places.

The Ministry of Education and Labour promotes sports programs and P.A. for children whose parents cannot afford to send them to class, also helping them in the purchase of specific clothing, footwear and equipment, the cost of which could otherwise prevent participation.

\begin{abstract}
Netherlands Learning together, performing well is a case study of a primary school in The Hague that integrates P.A. and P.E. throughout the curriculum. The school offers 3 hours of P.E. per week, with additional hours for sports such as martial arts, tennis and volleyball. The program also facilitates sports participation during and after school.
\end{abstract}

Poland School sports clubs is a program offered to primary and secondary schools to encourage P.A., especially among children and adolescents with poor physical fitness, providing more exercise, under the supervision of a teacher of P.A.. Lessons are held twice a week, for 60 minutes per session, with a minimum of 15 students.
The Ministry of Sport and Tourism activates a program through which it is possible to obtain financing for the construction or modernization of recreational infrastructures such as swimming pools, sports fields and outdoor gyms. The program aims to ensure that each municipality has a normal sized gym and each county has an indoor pool, increasing the overall number of recreational facilities. 


\begin{tabular}{ll}
\hline Portugal & CicloExpresso do Oriente (2015) consists of a group of \\
& children accompanied by adults, who make a trip to and from \\
school by bicycle. A sort of "bicycle train" that makes this \\
journey safer and more fun and facilitates greater future \\
autonomy for children and young people.
\end{tabular}

$\begin{array}{ll}\text { Slovakia } & \text { "To school on a bicycle" (2015) national campaign that } \\ \text { encourages elementary school children to go to school by } \\ \text { bicycle to increase their daily P.A.. A further national project to } \\ \text { improve the qualification of physical education teachers in } \\ \text { schools was implemented by the National Sports Center in } \\ 2015 \text { with the aim of training teachers to conduct 1-hour P.A. } \\ \text { sessions with modern methods and tools. }\end{array}$

Slovenia The surveillance system SLOfit

Since 1987 it is operating a surveillance system in Slovenia "SLOfit" to monitor the physical and motor development of children and adolescents. With the help of SLOFIT, children and their parents can monitor their physical and motor development, and physical education teachers have access to important information to enable children and adolescents with developmental problems for help and professional guidance. SLOFIT also collects information on the nutritional status of children, including body weight.

\section{Spain (Unidades Didacticas Activas (UDAs)), is an educational material developed by teachers specializing in the subject, aimed at increasing the percentage of intensity of P.A. of moderate to vigorous during physical education classes. \\ Data on assessment of a healthy physical condition \\ It is an official system for the community of Galicia, in which professionals in physical and sports activities monitor the physical conditions (physical fitness tests, including aerobic condition and strength) of individuals and groups. \\ Sweden The Importance of emphasizing outdoor environments for children's play, learning and health}

In the Swedish educational system, schools should provide all students P.A. during the school day, and students should develop the ability to move around and interest in being physically active and spending time outdoors in nature.

UK In Scotland, the "Active School" program offers more opportunities for higher quality participation in sport and P.A. before school, during the lunch hour and after school, and also develops effective pathways between schools and local sports clubs. Sport Scotland works in partnership with all 32 local authorities to invest and support the Active Schools Network.
The "U-Bike Portugal" promotes active transportation in academic communities through cycling. The Institute for Mobility and Transport coordinates the project, which hires bicycles for students and staff from academic institutions for a semester or an entire academic year.

A program of P.A. after school has been prepared to supplement the compulsory school curriculum and to prevent early school leaving, increase academic performance and accelerate learning through educational, recreational and leisure activities as well as personal development and social integration.

The "Grab a ball, not drugs" ("Zober loptu, nie drogy") The project in force since 2012 and is led by a nongovernmental organization. The goal is to involve children and adolescents in team sports in collaboration with 12 sports clubs in Slovakia. It also organizes information and educational campaigns, competitions and other sporting events.

The national program for nutrition and P.A. that improves health 2015-2025 includes measures to provide opportunities for socially disadvantaged groups to be physically active, including increasing the availability of open green spaces, the organization of sporting activities , promotion of recreational physical in nature and the promotion of active transportation.

The Swedish Sports is a traditional and democratic movement that is based on the active participation of volunteer leaders. A government regulation emphasizes that the work should enable all persons to practice sport and exercise, develop the interest of children and young people and promote a permanent interest, good health, integration and equal opportunities for boys and girls.

Sport England has launched his campaign on behaviour change "This girl can" (TGC) in January 2015 to ensure that more women aged between 14 and 40 years are physically active. The TGC encourages women and girls to be active, regardless of their shape, size or skill. 


\section{DISCUSSION}

As shown in the WHO document - More active people for a healthier world - it is important to ensure quality education for all girls and boys, in order to reduce sedentary behaviour and be physically active, to create better learning environments for all. Unfortunately, to date, the time allocated to physical education in some EU member states is insufficient to cover the recommendations of the WHO, thus assuming, in some cases a marginal role in the school curriculum, highlighting great differences between member countries, as is also underlined by the data emerging from the EUPEA Seminar meeting (November 2018) and from the various documents examined by the European Union. All Member States offer physical education classes in schools and most include 2 hours a week in the school curriculum. In many cases, the number of hours depends on school or national policies. Furthermore, in some countries such as Austria, physical education hours are not compulsory, but still present in the school program. In the Netherlands, physical education is a compulsory subject in primary education, although attendance and duration are not regulated by law, while secondary schools are obliged to include physical education classes during the school year based on to the question in terms of quality, intensity and variety.

In some countries, the importance of education through the movement is underlined by the fact that from the first class of nursery school there is a training program for physical education. This is the case in Denmark, which has a strong tradition for early childhood education and care, which with the Day-care facilities establish that all day care facilities must prepare for the pedagogical curriculum. The pedagogical curriculum will describe the local objectives of the nursery in relation to the learning of children within six themes, including the theme "body and movement". Also in France, in nursery school, there are psychomotor courses in the school curriculum.

A review of the various documents shows how ball games, athletics, gymnastics and dance are the activities commonly taught at school level both for primary and secondary education, while in some countries, physical education is taught with an interdisciplinary approach; in Slovenia, for example, teachers of subjects other than physical education are encouraged to occasionally interrupt their classroom lessons for "the health minute"; in this brief interruption the students carry out motor and relaxation activities. In Germany, on the other hand, the road rules for pedestrians and cyclists are part of the physical education curriculum. In Hungary, on the other hand, in addition to traditional sports with a recreational content, the philosophy of the new curriculum focuses on health objectives and cognitive content, which enables emotional and social development through motor activities.

Physical education teachers play an important role in promoting physical activity and sport among young people. The qualification of teachers is a very important aspect, but unfortunately today, in some countries the quality of preparation is variable and there are examples that suggest the lack of pedagogical and didactic inadequacy, endangering the importance of the subject and the quality of the learning of the pupils. A comparative reading of the selected documents shows that teaching in primary school, physical education is taught by both generalist teachers and specialized teachers, or both, depending on the availability of autonomy and school resources. Generally at primary level, the minimum qualification required is a university degree. In some countries, such as Italy, Germany and France, it can be taught by generalist teachers, who are required to teach everything. In other countries such as Bulgaria, Greece, Spain, Romania, only specialist teachers have the right to teach physical education at primary level. In secondary school, the European picture is more homogeneous as physical education teachers tend to be specialists and have a degree. 
The current trend is to reinforce the professional skills of teachers at primary level who need, especially if they are generalist teachers, to acquire appropriate professional skills through specific training.

Another problem that affects physical education is related to the quality and quantity of the provision of facilities and equipment, negatively affecting the quality of physical education, and very little has been done over the years. Research at European level shows that over a quarter of countries have inadequate facilities and facilities, and more than a third have limited or insufficient equipment.

Sport is an area where the EU's responsibilities were only introduced with the entry into force of the Lisbon Treaty in December 2009. Nevertheless, the EU's commitment has always been growing and the importance of sport and physical activity, is also confirmed by the Erasmus + program, a European program for education, training, youth and sport for the period 2014-2020. Every year about 38 million euros, equal to $1.8 \%$ of the annual Erasmus + budget, are allocated to activities related to sport. Actions in this area are aimed at promoting participation in sport, physical activity and volunteering through collaborative partnerships and organizing non-profit sports events. The Erasmus + Program supports the European week of sport, the initiative launched in 2014 that promotes sport and physical activity throughout Europe. The European week, which takes place in September, provides a series of sporting events in each Member State open at European, national, regional and local level in order to raise public awareness. During the 2014-2020 period, a specific budget line was made available under the Erasmus + program to support projects and networks in the sports sector in order to promote cooperation and the management of initiatives in support of the activity physics and sport in Europe.

\section{CONCLUSION}

The present study has drawn up a synthetic and detailed framework of the current status of physical education in the European school system. From a comparative analysis of the various states of the European Union emerge interesting data that offer various points of reflection.

Some member states promote innovative and adequate political responses that can serve as an example for other countries currently less committed to investing in the quality and quantity of physical education at school level. Over the years so much has been done, but in order to improve the European framework and have a more homogeneous perspective, Member States should create coordination mechanisms between sectors such as health, sport, education, transport, urban planning at national level, regional and local, in order to identify common objectives, to guarantee effectiveness, defined responsibilities and to have adequate resources and assessments.

Movement education and the promotion of physical activity are a formative task of the school. Starting from this assumption, physical education should represent, one of the main pillars of the educational path in school age. The importance of the subject has gradually strengthened over the years in all the Member States of the European Union to allow young people to be physically active during and after the school day. Nevertheless, only the real increase in the number of compulsory hours in some countries and the shared definition of quality standards could improve the status of physical education, realizing and finalizing the educational action of the scholastic world at the "Global Recommendations on physical activity for health" (WHO, 2018).

One way to achieve this goal could be to use an intersectoral approach that involves the education and sport fields also in the planning of physical education programs, to promote physical activity among students even 
in extra-curricular environments, with particular attention to reducing the most marked decline in physical activity among adolescent girls.

Schools, from kindergarten to high school should provide an adequate number of compulsory physical education lessons, improving the quality of the proposals, taking inspiration from the good practices already started in some member states. The lessons should integrate a variety of activities so that all children and teenagers can enjoy physical activity, regardless of their preferences and benefit from health benefits. This approach will provide positive trends that allow children and teenagers to lead physically active lifestyles and help them controlling fundamental motor skills.

The present study has certainly some weak points concerned mainly in the lack of documents and recent comparative scientific studies that analyse and synthesize through institutional sources the current framework of physical education in education and sports. The strength point in this regard is certainly that we have carried out an in-depth and summary study of the status of physical education in Europe by analysing the various ministerial documents of the member states and the project initiatives activated in expanding the educational offer and in the promotion of physical and sport activities in general and then synthesize the data by synthetic framework above highlighted in the tables. It is hypothesized to carry out, as a future study perspective, a detailed comparison on the school employees used in the various member states in the planning and didactic realization of school program and extracurricular sport activities, aware of the importance of investing more on professionalism and training of teachers than work in the school environment.

\section{REFERENCES}

Breda J., Jakovljevic J., Rathmes G., Mendes R., Fontaine O., Hollmann S., Rütten A., Gelius P., Kahlmeier S., Galea G. Promoting health-enhancing physical activity in Europe: Current state of surveillance, policy development and implementation. 2018. https://doi.org/10.1016/j.healthpol.2018.01.015

Colella D., Styles of teaching, motor learning and educational process Training \& Teaching XIV - 1-2016.

Dacica L., The role of physical education and sports. The 6th International Conference Edu World 2014 "Education Facing Contemporary World Issues", 7th - 9th November 2014.

D'Anna C. Physical education in the first cycle of education. From the founding nuclei to the didactic planning. Methodological suggestions and didactic suggestions. Volume 5 of Embodied Cognitive Science. New Culture Editions. 2018.

Di Maglie A., Sport for the health and well being of school age: the collected data, some pedagogical considerations Education \& Teaching XV - 2-2017.

EUPEA Seminar, How can I raise the status of PE? 2018 https://www.eupea.com/

European Commission/EACEA/Eurydice, 2013. Physical education and school sports in Europe. Eurydice report. Luxembourg: Office for European Union publications. http://eurydice.indire.it/pubblicazioni/educazione-fisica-e-sport-a-scuola-in-europa/

European Commission Recommendations to encourage physical education in schools, including motor skills in early childhood, and to create valuable interactions with the sport sector, local authorities and the private sector, EU Work Plan for Sport 2014-2017 https://eacea.ec.europa.eu/sites/eaceasite/files/recommendations_pe_at_schools_2015.pdf

European Commission Sport and physical activity (Special Eurobarometer 472). Brussels. 2018.

European Commission What is Erasmus+ https://ec.europa.eu/programmes/erasmus-plus/about it 
Hardman K.. The situation of physical education in schools: a European perspective. Human movement, 2008, vol. 9 (1), pp. 5-18.

Katsarova I., Physical education in EU schools, EPRS European Parlament Research Service, 2016 http://www.europarl.europa.eu/RegData/etudes/BRIE/2016/593559/EPRS_BRI(2016)593559_EN.p df

Katsarova I. Sport and physical activity in the European union. European Union, Eurobarometer, $\begin{array}{lll}\text { Eurydice. } & \text { September } & 2017\end{array}$ http://www.europarl.europa.eu/EPRS/Sport_and_activity_in_the_EU_September2017 web.pdf

Le Lostecque Y. EU Work Plan for Sport 2014-2017, EU Sport Forum 2016 http://ec.europa.eu/assets/eac/sportforum/docs/6-1-euworkplan-ec.pdf

Mantjes, J.A., Jones, A.P., Corder K. et al. School related factors and $1 \mathrm{yr}$ change in physical activity amongst 9-11 year old English schoolchildren. Int. J. Behav. Nutr. Phys.Act. 9, 153. 2012. https://doi.org/10.1186/1479-5868-9-153

National Institute of Health Surveillance System to OKkio HEALTH: 2012 risults. ISTISAN 12/42 Reports.

Ottonello P., Sport and physical activity in the UE. European Commission 2014 http://esport.gencat.cat/web/.content/home/arees dactuacio/ativitat fisica salut/pnpaf PlaNacPro mActFis/jornades-internacionals/Jornadalntern_121214/14-12-12_Jorn_Inter_present.pdf

WHO Regional Office for Europe Physical activity strategy for the WHO European Region 20162025.Copenhagen; 2016.

World Health Organization ACTIVE: a technical package for Increasing physical activity. Geneva; 2018. License: CC BY-NC-SA 3.0 IGO. https://apps.who.int/iris/handle/10665/275415?show=full

WHO Regional Office for Europe Global action plan on physical activity 2018-2030: More active people for a healthier world. Copenhagen. 2018. https://apps.who.int/iris/handle/10665/272722

WHO Regional Office for Europe Promoting physical activity in the education sector. Current status and success stories from the European Union Member States of the WHO European Region 2018 WHO Regional Office for Europe; 2018.

WHO Regional Office for Europe Factsheets on health-enhancing physical activity in the 28 EU Member States of the WHO European Region 2018 Copenhagen: WHO Regional Office for Europe; 2018.

XY Wu, Han LH, Zhang JH, Luo S, Hu JW, Sun K The influence of physical activity, sedentary behavior on health-related quality of life among the general population of children and adolescents: A systematic review. PLoS ONE 12 (11). 2017. https://doi.org/10.1371/journal.pone.0187668

\section{Websites}

Austria

https://bildung.bmbwf.gv.at/schulen/bw/index.html

https://www. fitsportaustria.at/main.asp?VID=1\&kat1=94\&kat2=666

Belgium

https://onderwijs.vlaanderen.be/

Bulgaria

https://eacea.ec.europa.eu/national-policies/eurydice/content/bulgaria_en

Croatia

https://www.google.com/search?biw=1580\&bih=768\&ei=RiHuXMSTPIzTkgXuj4iwBg\&q=https\%3A\%2F \%2Fwww.hzjz.hr\%2Fwp-content\%2Fuploads\%2F2016\%2F10\%2FPOLIGON-ZA-

TJELESNUAKTIVNOST-\%25C5 \% 25AOKOLSKE-DJECE.pdf \& oq $=\mathrm{https} \% \quad 3 \mathrm{~A} \% \quad 2 \mathrm{~F} \%$ 2Fwww.hzjz.hr\% 2Fwp-content\% 2Fuploads\% 2F2016\% 2F10\% 2FPOLIGON-ZATJELESNUAKTIVNOST- $\% \quad 25 C 5 \% \quad 25$ AOKOLSKE-DJECE.pdf \& gs_l = psy-ab.3. 


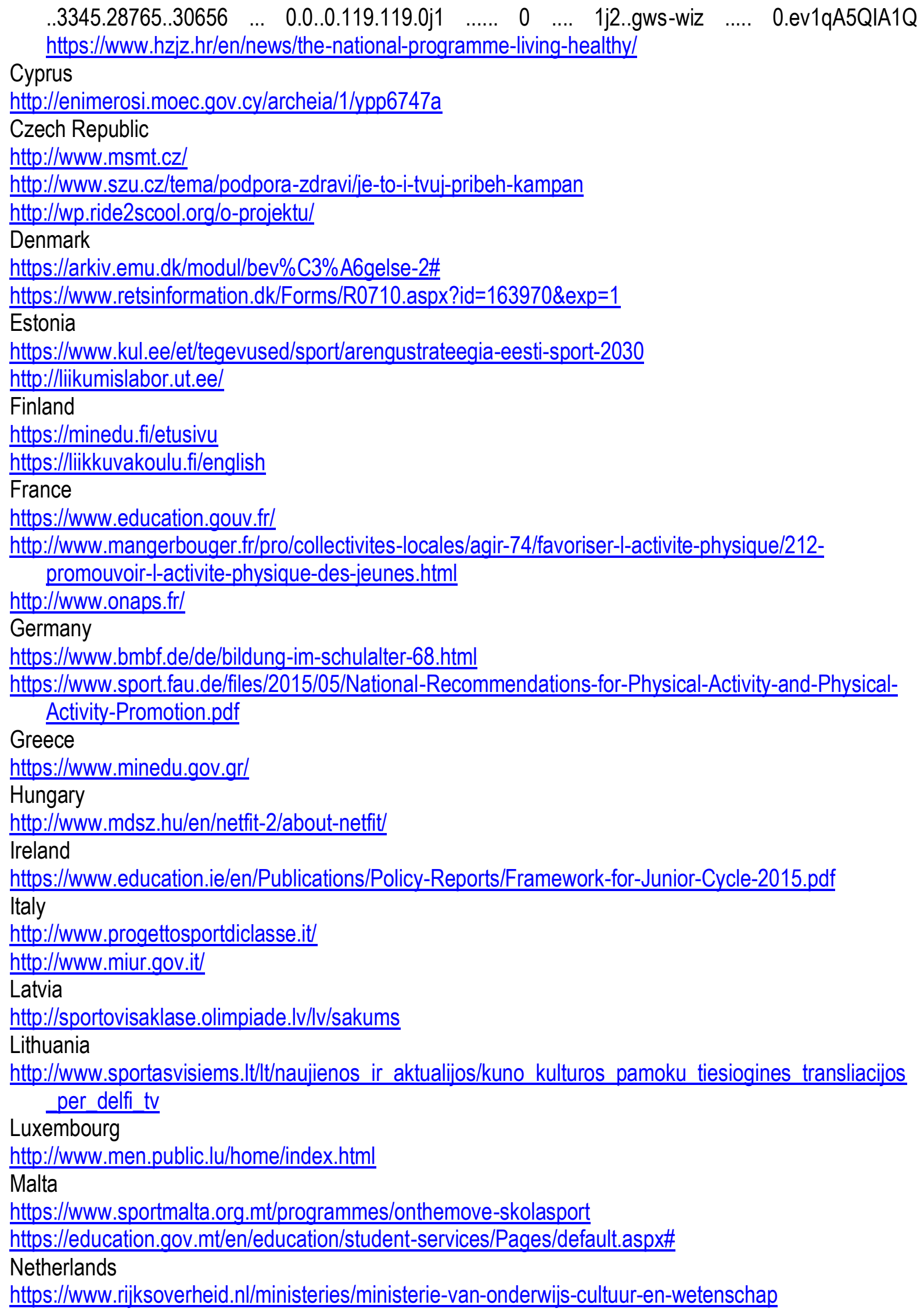




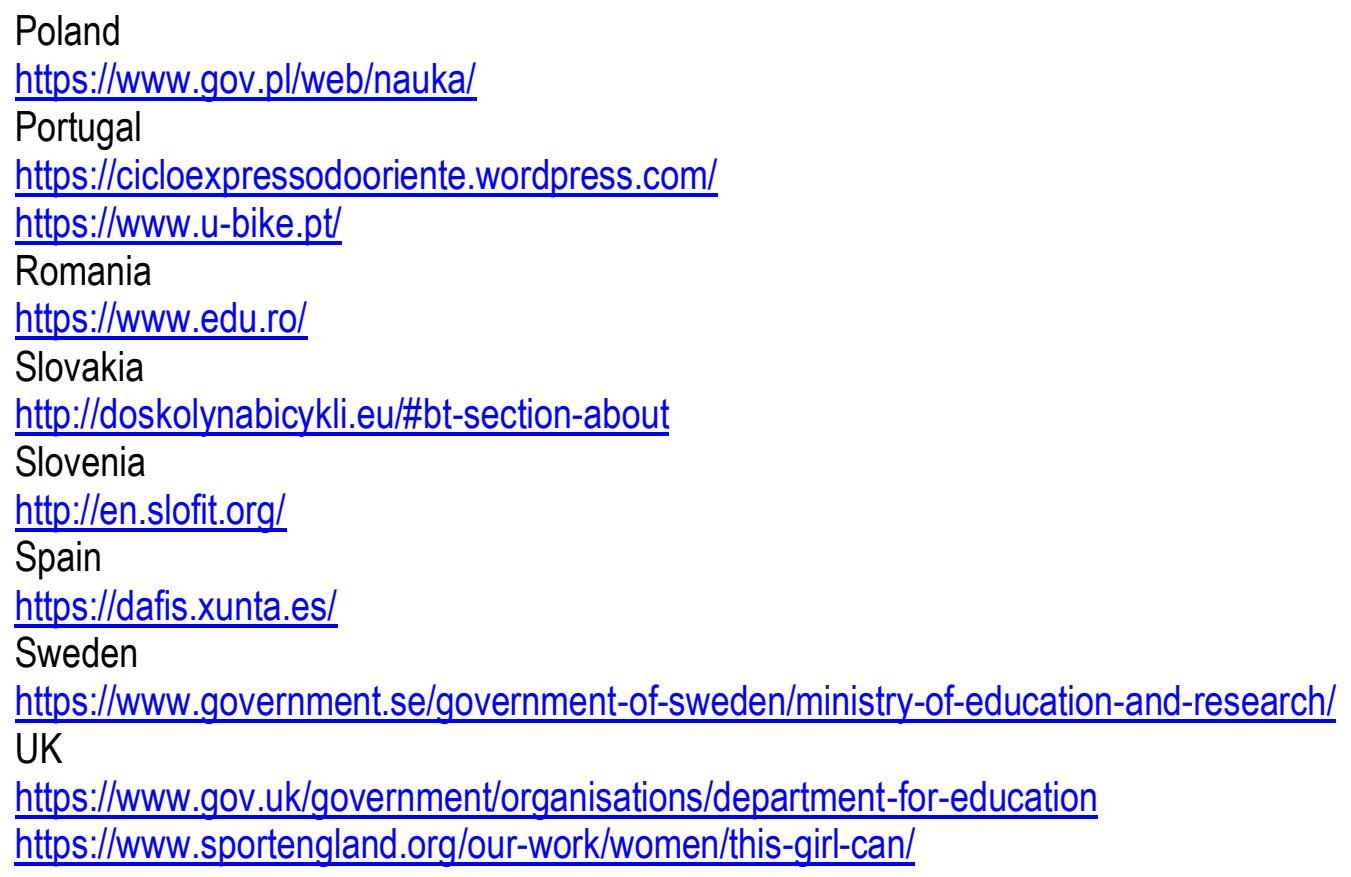

